\title{
The Taylor Rule and Financial Derivatives: The Case of Options*
}

\author{
Chiara Oldani
}

\subsection{Introduction}

Modern macroeconomics considers the role of financial assets when modelling the behaviour of agents, policy implementing and transmission mechanisms. Financial innovation emerges in markets and exploits new opportunities, giving rise to (new) profits. The most significant financial innovations of the last thirty years have been in the area of derivatives (futures, options, swaps and forwards). The amount of derivatives trading is steadily growing on both exchange traded (ET) markets and OTC, and it is this growth that accounts for the present interest in these areas. According to BIS data, the ratio between the notional amount outstanding of derivatives (exchange traded and OTC) and world GDP was equal to 3.73 in 2001 and to 6.68 in 2004. Options are by far the most common derivatives contracts in ET markets. The role of derivatives in asset pricing is widely known and accepted. Here I shall start from their economic functions (leverage, substitutability, hedging) (Savona, 2005 and 2003) in order to conduct further macroeconomic analysis.

Monetary policy should concern itself with financial innovation because such innovation modifies the effectiveness of policy implementing and its ability to achieve predefined goals (e.g. price and financial stability) (Vrolijk, 1997). The New Keynesian model (Woodford, 2003) represents optimizing conditions in the presence of real frictions. Significant financial innovation should be considered in policy making, both fiscal ${ }^{1}$ and monetary, and with

\footnotetext{
* I wish to thank Rocco Ciciretti, Domenico Cuoco, Giorgio Di Giorgio, Salvatore Nisticò, Alberto Petrucci, Paolo Savona, and Carlo Viviani for their very useful comments. My special thanks go to Cristiano Zazzara for his valuable help. This research has been developed during a visiting period at the Dept. of Finance, Wharton School, University of Pennsylvania, Spring 2005, and presented at the Dept. of Economics of Luiss Guido Carli University in May 2005 and at the International Conference on Keynesian Legacy, at the University of Cassino in September 2005.
} 
respect to coordination for the purpose of controlling inflation and achieving market stability.

The study is structured as follows: section 4.2 describes the main features of New Keynesian macroeconomics and monetary policy; section 4.3 sets out the reasons why options should be included in a monetary rule; section 4.4 describes the modified monetary policy rule; section 4.5 shows the longrun solution of the model; section 4.6 presents some preliminary empirical results. A brief conclusion draws together the main findings.

\subsection{The New Keynesian economic approach to monetary policy}

On the New Keynesian view as put forward by Woodford (2003), monetary policy and central banking are an Expectation Management Exercise, so that the ability to influence expectations is of central importance in achieving stability. The private sector should be forward looking, and future market conditions are important determinants of current agents' behaviour (Woodford, 2003: 15). Policy implementing through a forward-looking rule, when the private sector is also forward looking, gives rise to sub-optimal results. Systematic rules linked to past values of target variables (income, price, interest rate) are therefore necessary to respond to random disturbances. These are the main justifications for the Taylor rule.

Monetary policy can be implemented by an interest rate rule in a 'pure credit economy' first described by Wicksell (1898) more than a century ago, where no money or currency is necessary to finance consumption, trade or investment. This is not simply a cashless society, as argued by the Money From the Helicopter Theory, but a modern electronic-based transactions and payments system. Criticism of the interest rate rule refers to the possibility that there may be multiple equilibria. But this is true if the interest rate rule relies on exogenous evolution of the variables, not if such evolution is endogenous. ${ }^{2}$

The commitment of the monetary authority should be specified on nominal interest rates, not real ones, which are driven also by other variables not entirely under the central bank's control. Formally, a (Federal Reserve reaction) function, as introduced by Taylor, can be specified as

$$
r_{t}=\bar{r}+\phi_{\pi}\left(\bar{\pi}_{t}-\bar{\pi}\right)+\phi_{x} x_{t}
$$

where $r_{t}$ is the interest rate (Federal Fund rate), $\bar{r}$ the natural rate, $\bar{\pi}_{t}$ the inflation rate, $\bar{\pi}$ the target of inflation, and $x_{t}$ the output gap. Partial adjustment can be introduced, for example, through a lagged interest rate or an output gap. This rule represents the basic monetary rule in New Keynesian frameworks. 
Carare and Tchaidze (2005) point out that a simple policy rule like Taylor's has been abused as a tool for policy setting. On observing the poor data fit yielded by the simple Taylor rule, numerous authors have tried to add lagged or forward-dependent variables. I do not agree with the sceptical view expressed by Carare, since the evolution of markets and agents cannot be captured by the variations in inflation and output gap alone. Financial innovation is the manifestation of the evolution of markets. By considering an innovative, though representative instrument, I shall seek to enrich the Taylor rule with a powerfully informative variable.

\subsection{The role of options on monetary and financial markets and management}

Financial innovation is a variable considered responsible for money demand instability and for altering financial markets. The aim of the monetary policy rule in New Keynesian models is not to control money supply but to achieve inflationary and financial stability (Woodford, 2003). Hence financial innovation should be considered in monetary policy operating procedures if it is able to alter the ability to achieve the desired stability of goods prices and of financial markets.

Financial innovation broadly defined (derivatives, securitisation, e-money and so on) can have various effects on monetary policy transmission mechanisms.

\begin{tabular}{ll}
\hline Monetary policy channels & Effects \\
\hline Interest rates & Market liquidity \\
& Cost of capital \\
Valuation & Wealth (consumption) \\
& Capital valuation (investments) \\
& Exchange rates (net exports) \\
Credit & Bank lending \\
& Balance sheet \\
\hline
\end{tabular}

Source: Estrella (2001).

According to Estrella, derivatives have various effects on all channels of monetary policy. They positively influence market liquidity and the cost of capital by increasing market efficiency; and they influence wealth and capital valuation (in periods when capital markets are not subject to exogenous shocks), although they do so in an (empirically) unclear manner because the influence depends mostly on the (economic) function for which they are used (hedging, leverage or substitution). Extensive use is made of derivatives for exchange rate hedging. The effects on banks' lending and balance sheets depend upon the functions of derivatives, and they are mixed. The scant 
empirical evidence surveyed by Estrella confirms that treating derivatives as a general category of financial instruments leads to almost inconclusive results.

The problem is identifying the data on derivatives used for hedging, leverage and substitution. Current accounting rules (and Basle II or IAS-FASB rules) have the merit of letting derivatives enter firms' balance sheets (they are no longer off-balance-sheet items), but not yet with their explicit (economic) function, so that the (poor) empirical evidence has not improved.

Derivatives are by far the most commonly traded financial assets on exchange traded markets and OTC; derivatives increase the liquidity of (underlying) financial markets and are efficient at microeconomic level. ${ }^{3}$ Within the broad category of derivatives, option contracts can be considered to be the most attractive assets, owing to their leverage effects and high flexibility. Their implied volatility is the key parameter used for pricing and to analyse their efficiency.

Financial innovation modifies the ability of monetary policy to achieve predefined targets and alters its policy rules setting. Vrolijk (1997) argues that derivatives have accelerated the transmission mechanism in financial markets, so that monetary policy is no longer able to use the surprise effect.

As underlined by Savona $(2003,2005)$, the functions on whose basis derivatives are used by investors drive the investment decision; if we cannot disentangle the motives for investments and then the amount of derivatives bought or sold for hedging, substitution or leverage, we cannot infer anything for a specific theory on the role of derivatives at the macroeconomic level. This is by far the greatest weakness in all the (empirical) derivatives literature of recent years.

However, an empirical limitation does not impede theoretical analysis. Given the important role of derivatives in financial markets, especially since the 1980s, addressing their impact on monetary policy rule can no longer be postponed.

The New Keynesian monetary policy rule should be implemented by considering those variables relevant to achieving stability. Financial markets in this type of model are perfect (frictions are mainly in the real sector, i.e. wage and consumer preferences), so that we can apply the Black and Scholes framework to analyse the role of derivatives in the model. The monetary policy rule is based on the interest rate setting. Given that it is possible to determine that a positive relationship exists between the implied volatility of option contracts and the (risk-free) interest rate (Brenner and Subrahmanyam, 1988), and that there is a positive relationship among the expected volatility of equity prices, information about real activity and inflation, and the path of monetary policy reflected in the interest rate (Kearney and Lombra, 2004), it is reasonable to introduce the implied volatility into the Taylor rule as an explanatory variable.

The policy rule sets the interest rate in response to certain perceived risks. The existence of a (positive) relationship between the interest rate and the 
implied volatility, and among the expected volatility of equity prices, information about real activity, inflation and the path of monetary policy reflected in the interest rate, helps us in implementing the policy rule with an option contract written on the (representative) equity price. In the US economy, the principal equity price is the Dow Jones Industrial Average index, and the corresponding option contract written on this index is the chosen derivative.

\subsection{The Taylor rule}

The Taylor rule can be described by an augmented interest rate rule taking the form:

$$
r_{t}=\phi E_{t} \pi_{t+1}+\psi x_{t}+\rho r_{t-1}+\delta \sigma_{t}
$$

where $x_{t}$ is the output gap, $r_{t}$ the nominal interest rate, $\pi_{t+1}$ the inflation rate, $E_{t}$ the expectation operator, and $\sigma_{t}$ the implied volatility of options. The lagged interest rate $\left(r_{t-1}\right)$ represents the inertia of monetary policy, and its coefficient $(\rho)$ should be less than one but greater than zero.

The implied volatility is supposed to behave like an AR(1) shock, i.e.:

$$
\begin{aligned}
& \sigma_{t}=\omega \sigma_{t-1}+\varepsilon_{t} \\
& \varepsilon_{t} \approx(\mu, V A R) \approx \chi^{2}
\end{aligned}
$$

The error term of the monetary rule $\left(\varepsilon_{t}\right)$ is a random shock, with a given mean $(\mu)$ and variance $(V A R)$, and it is distributed like a $\chi^{2}$, which is a positively-skewed distribution and allows for asymmetric effects of increasing versus decreasing volatility. In fact, the authority should react to higher (increasing) volatility by acting on the (nominal) interest rate, while, in the case of decreasing volatility, a less strong monetary reaction is supposed to take place.

Expectations about the interest rate influence the behaviour of investment demand and supply, thereby affecting aggregate demand, growth and prices. In the standard New Keynesian model the last term of eq. $4.2\left(\delta \sigma_{t}\right)$ is not present because the monetary policy rule is not supposed to react to expectations in the financial market. My intention in introducing expectations about the interest rate into the monetary rule is to stress the informational content of options, which are used by policy makers to extract future expected price patterns. This is rational behaviour because it acknowledges their economic and informational content, together with their high liquidity, efficiency and diffusion across worldwide markets. ${ }^{4}$

Since modern monetary policy does not consider price rules $\left(\phi E_{t} \pi_{t+1}\right)$ without also having some concern for growth, it seems reasonable to include expectations about an important instrument into the policy rule, which has a long-run relationship with prices. This, of course, makes the behaviour of 
monetary policy subject to two different expectations-setting mechanisms, those concerning inflation and volatility. The Taylor rule is itself suboptimal, regardless of its specification, and the relevance has to be put over stabilisation and expectations management.

If the implied volatility of options is subject to instability (that is, it increases or decreases because of unanticipated shocks), the behaviour of monetary policy is not specified in such a way that the interest rate will jump to the same extent. The Taylor rule is not an automatic policy rule; rather, it is a behavioural function of modern policy making.

Changing expectations about growth affect the natural rate of interest desired by the authorities, and, in this specification, it affects the interest rate rule via the equilibrium setting. The monetary and fiscal authorities have expectations about important economic variables. The recent literature and common sense also show that policies coordination on targets and instruments can give rise to a better equilibrium, so that the explicit introduction of the natural rate into the interest rule is justified. The Austrian School recognised that human manipulation influences the level of the natural interest rate, because it is determined by the interaction between demand and supply and is heavily affected by expectations.

Monetary policy is responsible for long-run price stability and growth stimulation through its instruments. Expectations about prices are a fundamental part of the strategy, but growth should not be sacrificed, as shown by the Federal Reserve's behaviour.

\subsection{The long-run solution}

The macro model can be solved in the long run, starting from the reduced form:

$$
E_{t} Z_{t+1}=A Z+a r_{t}^{n}+b \varepsilon_{t}
$$

where $A$ is a $4 \times 4$ matrix and $a, b$ are $1 \times 4$ vectors. The complete algebra is given in the appendix, but as shown by Woodford (2003), a stable equilibrium exists iff two eigenvalues of matrix $A$ are inside the unit circle. ${ }^{5}$

Matrix A is:

$$
\left(\begin{array}{cccc}
1 / \alpha & 0 & 0 & 0 \\
\frac{-\theta+\varphi \gamma}{\alpha \beta}-\frac{\lambda}{\alpha} & \frac{1}{\beta} & \frac{\varphi}{\beta} & 0 \\
-\frac{\psi}{\alpha}+\frac{\rho \gamma}{\alpha} & 0 & \rho & 0 \\
\frac{\omega \delta \gamma}{\alpha} & 0 & \omega \delta & \omega
\end{array}\right)
$$


Eigenvalues of matrix A can be represented as:

$$
\left(\begin{array}{llll}
\rho & \omega & \frac{1}{\alpha} & \frac{1}{\beta}
\end{array}\right)
$$

and, since $\rho<1$, and $\omega<1$, the equilibrium condition is satisfied. $\rho$ is the inertia of the interest rate, and $\omega$ is that of the implied volatility. Both inertias are less than one, otherwise there would be overshooting phenomena.

\subsection{Empirical evidence}

Many authors agree that the Taylor rule should be implemented with forwardlooking variables if it is to be optimal. We know from the model setting that monetary policy with rational optimizing agents can set a linear rule of contemporaneous variables because the forward-looking component is incorporated into the agents' behaviour. Then it becomes simply a matter of specifying the model coherently. In our setting, agents are forward looking, so that the policy rule can be specified in terms of contemporaneous variables. The implied volatility of options serves the purpose of incorporating the expectations of financial markets and then signals the expected future behaviour of markets.

Increasing implied volatility signals financial market turbulence. Monetary policy should react by strengthening the money stance (increase the interest rate); if the volatility is decreasing, the reaction may be asymmetrical in that it does not reduce the interest rate by the same amount. This stylized fact is incorporated into the asymmetrical shape of the epsilon shock.

In what follows, the quarterly data used for estimation over the period 1998-2005 are taken from the Thomson Financial Datastream and Bloomberg; $x_{t}$ is the Holdrick-Prescott filtered output gap computed from the US output gap, defined as the deviation of the actual GDP from its potential, as a percentage of potential GDP. The interest rate $\left(r_{t}\right)$ is the Federal Fund rate and is expressed in percentage terms; the expected inflation rate $\left(E_{t} \pi_{t+1}\right)$ is taken from the US consumer opinion survey; the implied volatility $\left(\sigma_{t}\right)$ is computed by Bloomberg using their own algorithm, and it refers to the option contracts (put and call) on the Dow Jones Industrial Average index. ${ }^{6}$ These contracts are the most frequently traded, liquid and representative of the entire US market. They are traded at the Chicago Board Option Exchange, the biggest option exchange in the world, and are among the very first contracts to be settled, so that a 'long' time series is available.

The econometric estimate starts with analysis of the variables' behaviour. Over the period 1998-2005 inflation was not a major phenomenon in the US, and it was not a particular concern for the monetary policy authority. ${ }^{7}$ The inflation rate was between 2 and 4 per cent in the presence of sustained growth (Figure 4.2). We may therefore conclude that either the coefficient of 


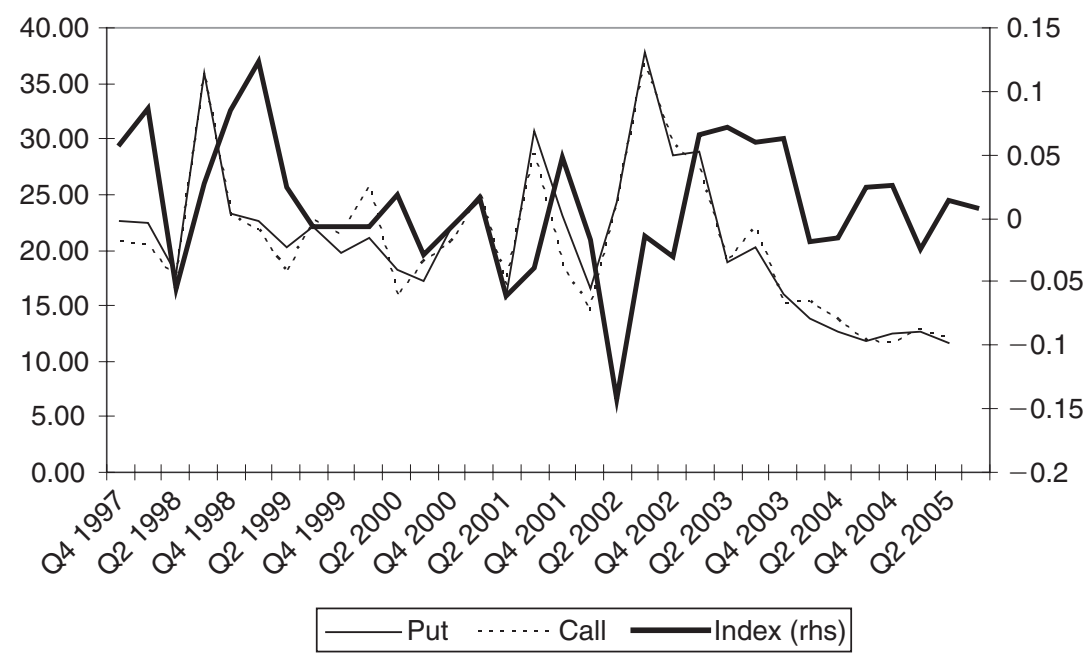

Figure 4.1 Implied volatility of DJIA options and the variation of the underlying stock index

Source: Own elaboration on Bloomberg and Thomson Financial Datastream data.

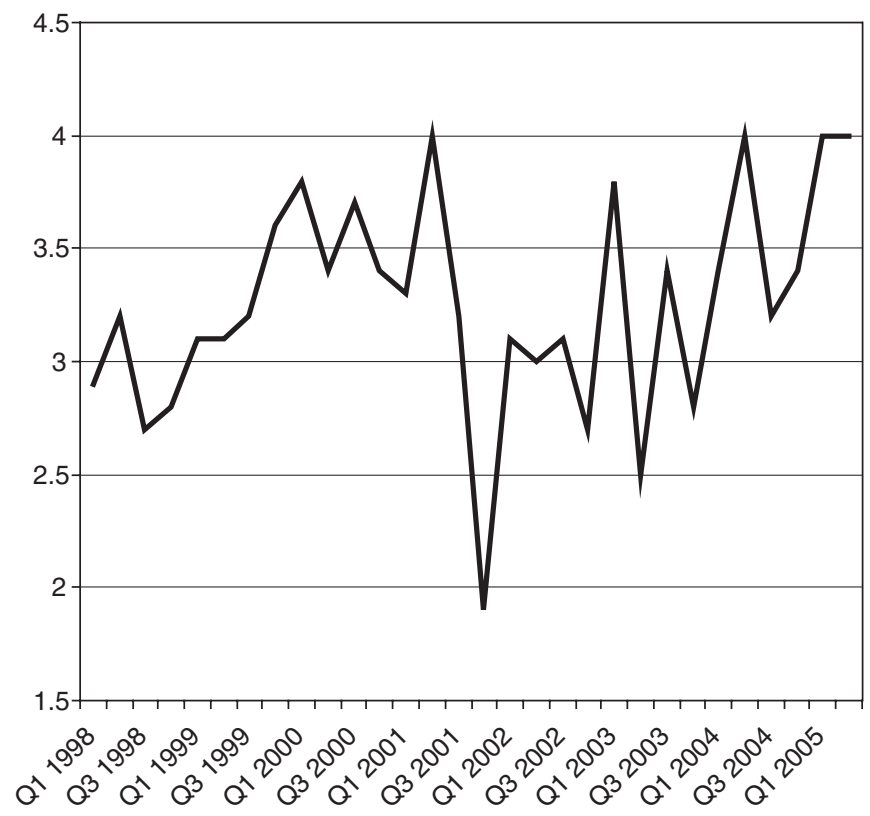

Figure 4.2 US expected inflation rate (\%)

Source: Own elaboration on Thomson Financial Datastream data. 
the inflation rate in the Taylor rule is not significant, or that its sign is not particularly meaningful. The output gap exhibited negative values throughout most of the period, i.e. the US economy performed very well. The US Fed fund rate increased until the end of 2000, when monetary policy switched to being expansionary. The maximum interest rate was 6.47 per cent and the minimum was 1 per cent. The implied volatility varied between 38 and 12, and its shape was very similar to that of the variation in the underlying stock index.

The Taylor rule (eq. 4.2) has non-stationary variables and was estimated using different specifications and econometric methods. According to the literature $^{8}$ and the model, the function should be specified in terms of contemporaneous variables, but the lagged interest rate is meaningful and represents the inertia of the policy. I estimated the function first without the implied volatilities; ${ }^{9}$ as a second step, I included the implied volatility of call and put. ${ }^{10}$ The complete results are set out in the appendix to this chapter.

The estimators used were the Least Squares (LS) and the Maximum Likelihood (ML). The LS estimator yielded super-consistent coefficients owing to the non-stationarity of the variables, ${ }^{11}$ which were $\mathrm{I}(1)$. The ML estimator yielded consistent coefficients, and considered the autoregressive effect due to the presence of unit roots. ${ }^{12}$

The LS results confirm that inflation did not play a role in monetary policy setting in the period 1998-2005: its coefficient is either very small or not statistically significant. Fed Board members never expressed particular worries about inflation during the period; they paid most attention to growth ${ }^{13}$ and the stability of financial markets'. Stock exchange exuberance, the consequent financial turbulence and the number of corporate crises experienced by the US during the period were the main sources of concern for the Fed.

The ML results are consistent econometrically and interesting in terms of magnitude, but they confirm that inflation was not a cause of concern for the Federal Reserve. The inertia of the interest rate was high, as many other authors have observed, and the output gap was an important variable in the period (1998-2005): its coefficient varied around 0.40. ${ }^{14}$ The implied volatility (of put and call options) was significant in the Taylor rule; its coefficient was small, a finding which can be explained by the fact that the informative content deriving from the Dow Jones Industrial Average was a portion of the entire information set available in the US economy, as well as by the fact that the implied volatility did not vary greatly over the period under analysis, while the Fed made active use of the interest rate. If the goal of monetary policy is to achieve financial stability, the information furnished by the Dow Jones index is important because the wealth invested in the stock exchange is a large share of the total.

The main econometric findings can be briefly synthesised as follows:

- inflation was not a concern for the US monetary policy authority during the period 1998-2005; 
- the output gap was the main goal of Federal Reserve policy;

- the volatility of options can be a useful source of information and then could be used to implement the policy rule.

The Taylor rule results are consistent with public statements by the Federal Reserve, which focused mainly on growth and the maintenance of financial stability.

The long-run model specification and econometric solution are set out in the appendix to this chapter. However, given the lack of complete data on derivatives amounts outstanding, counterpart distribution and balance sheet effects, they are not fully reliable for further inferences to be drawn.

\subsection{Concluding remarks}

This study has explicitly considered the role of financial derivatives, namely options, in a macroeconomic monetary rule. The New Keynesian model rebuts the criticisms brought against the IS-LM and AS-AD frameworks, and it adds meaningful real rigidities for the consideration of the realworld behaviour of agents, markets and institutions. Numerous criticisms have been made of these models, especially by neoclassical economists. Nevertheless, I maintain that they aid the understanding of the economic transmission mechanism by considering real rigidities and shocks in an optimising microeconomic framework.

Financial innovation plays a prominent role in the evolution of financial markets, and its disruptive/creative process is considered within the transmission mechanism when it becomes of significant magnitude. Modern monetary policy uses an instrument - the interest rate - to attain price and financial stability; while financial innovation influences monetary channels and the ability to achieve both targets. The recent literature has shown that there is a positive relationship between the implied volatility and the interest rate, and, moreover, that it can be used for monetary policy.

The Taylor rule modified in order to consider the implied volatility of option contracts yields encouraging empirical results on the basis of US data. The long-run (state-space) solution to the model exists and confirms that a stable equilibrium can be achieved. However, the economic exercise is heavily affected by the short length of the data available, and by the complete absence of data on the economic function of derivatives use. It is consequently not fully reliable for the purpose of drawing further inferences.

The main econometric findings with regard to the US in the period 19982005 at a monthly level can be briefly summarised as:

- inflation was not a concern for the US monetary policy authority in the period 1998-2005;

- the output gap was the main goal of Federal Reserve policy; 
- the implied volatility of options on the Dow Jones Industrial Average Index is a useful source of information and implements the policy rule.

The Taylor rule results are consistent with public statements by the Federal Reserve, which were focused mainly on growth and on the maintenance of financial stability during the period. The information furnished by the Dow Jones Index is important because wealth invested in the US stock exchange is huge.

This study has been a first attempt to take explicit account of the role of options in macroeconomics. The macro-analysis of financial phenomena like asset innovation is new to New Keynesian economics, and it has yielded some encouraging preliminary results.

In this largely unexplored area of the literature on both finance and economics, further research on the relationship between asset prices and monetary policy - as urged by Alan Greenspan in his Jackson Hole speech of August 2005 - must necessarily remedy the lack of detailed and comprehensive data on derivatives contract volumes, counterparts, and geographical distribution. This is a shortcoming that we cannot overcome in the short run. But in the long run we are all dead.

\section{Appendix}

\section{A Model specification}

The short-run model with explicit parameters can be described by the following equations:

$$
\begin{aligned}
x_{t} & =\alpha E_{t} x_{t+1}-\gamma r_{t}+\eta r_{t}^{n}+\theta E_{t} \pi_{t+1} \\
\pi_{t} & =\beta E_{t} \pi_{t+1}+\lambda x_{t} \\
r_{t} & =\phi E_{t} \pi_{t+1}+\psi x_{t}+\rho r_{t-1}+\delta \sigma_{t} \\
\sigma_{t} & =\omega \sigma_{t-1}+\varepsilon_{t} \\
\varepsilon_{t} & \approx \chi^{2}
\end{aligned}
$$

\section{B The analytic solution to the model}

Characteristic polynomial of a matrix is of the form:

$$
x^{4}+A_{3} x^{3}+A_{2} x^{2}+A_{1} x+A_{0}
$$

Substituting the values of $A$ matrix we obtain:

$$
\begin{aligned}
x^{4} & -\frac{(\omega \alpha \beta+\rho \alpha \beta+\alpha+\beta)}{\alpha \beta} x^{3}+\frac{(\omega \rho \alpha \beta+\omega \alpha+\omega \beta+\rho \alpha+\rho \beta+1)}{\alpha \beta} x^{2} \\
& \pm \frac{(\omega \rho \alpha+\omega \rho \beta+\omega+\rho)}{\alpha \beta} x+\frac{\omega \rho}{\alpha \beta}
\end{aligned}
$$


Eigenvalues are:

$$
\frac{1}{\alpha} \quad \frac{1}{\beta} \quad \omega \quad \rho
$$

\section{Option pricing and volatility}

The Black and Scholes (1973) option pricing formula is given by:

$$
\begin{aligned}
C & =S \Phi\left(d_{1}\right)-X e^{-r t} \Phi\left(d_{2}\right) \\
P & =X e^{-r t} \Phi\left(-d_{2}\right)-S \Phi\left(-d_{1}\right) \\
d_{1} & =\frac{\log (S / X)+\left(r+\sigma^{2} / 2\right) t}{\sigma \sqrt{t}} \\
d_{2} & =d_{1}-\sigma \sqrt{t}
\end{aligned}
$$

where $C$ is the price of the call option, $P$ the put price, $S$ the spot price of the underlying asset not paying a dividend or carrying transaction or storage costs, $X$ the strike price of the option, $r$ the risk-less rate of interest, $t$ the length of the option contract, $\Phi$ the standard normal, and $\sigma$ the volatility of the underlying asset.

The no-arbitrage condition in option markets implies that put/call parity should hold $\forall t$; then:

$$
C+X e^{-r t}=P+S
$$

The option price is set on the basis of the no-arbitrage condition, and the volatility of the underlying asset, extracted from the option price (i.e. having $C, P, X, S, r, t$ compute $\sigma$ ), is key variable for financial engineers to price other derivatives written on the same underlying but not widely traded (Black, 1976).

Since asset prices $S$ are considered to be stochastic processes, independently and identically distributed (iid), their volatility is the standard deviation of their (log) returns. Theoretically, when starting from different option contracts written on the same underlying, the implied volatility should be the same, confirming the goodness of the log-normal hypothesis and of stochastic asset prices.

I am aware that different volatility can be computed on the same underlying statistics depending on the strike price, and the length of the option contract. The plot of $\sigma$ is usually called the 'volatility smile' (or skew), and it is the function used by financial engineers to price other derivatives written on the same underlying. This violation of the Black-Scholes formula can be justified by a non-log-normal distribution function and/or a non iid process of asset prices in real financial markets, where transaction costs, liquidity constraints, asymmetric information play a role. 


\section{Statistical data}

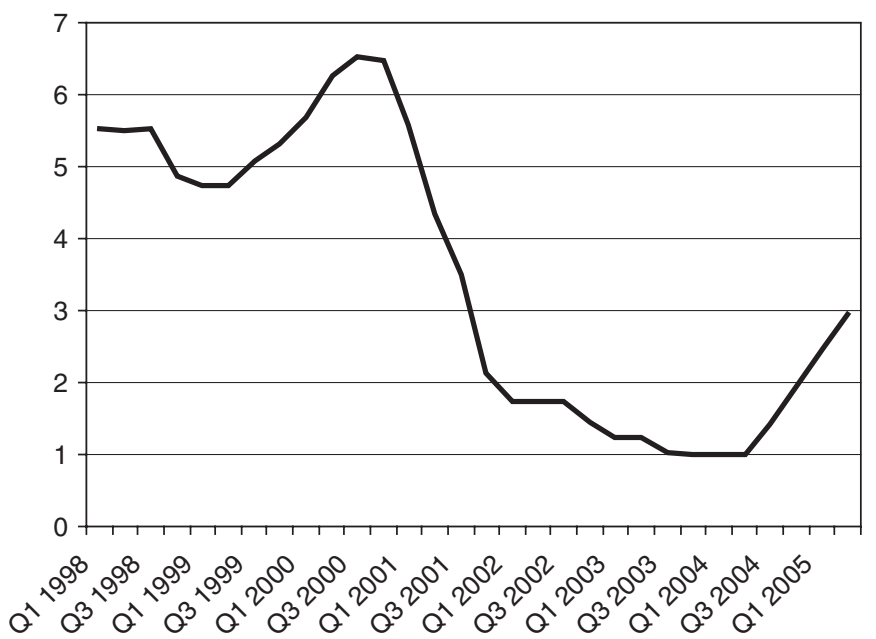

Figure 4.3 US Federal fund rate (\%)

Source: Own elaboration on Thomson Financial Datastream data.

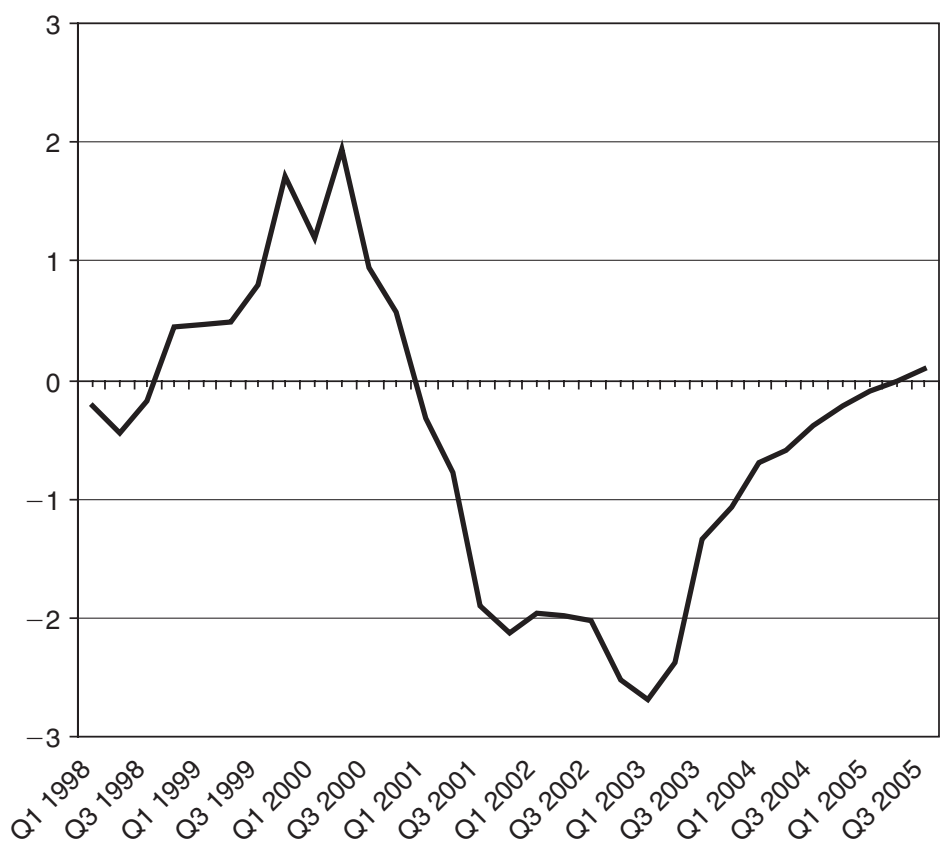

Figure 4.4 US Output Gap as \% of Potential GDP

Source: Own elaboration on Thomson Financial Datastream data. 


\section{E Econometric results}

Table 4.1 Unit root test, 1998Q1-2005Q2

\begin{tabular}{lcc}
\hline Variable & Phillips Perron & P value \\
\hline Interest rate & -1.1597 & 0.2188 \\
Diff(interest rate) & -2.1381 & 0.0334 \\
Inflation & 0.0449 & 0.6894 \\
Diff(inflation) & -6.8825 & 0.0000 \\
Output gap & -1.7352 & 0.0783 \\
Diff(output gap) & -4.6742 & 0.0000 \\
Put & -0.9175 & 0.3109 \\
Diff(put) & -9.9892 & 0.0000 \\
Call & -0.8915 & 0.3217 \\
Diff(call) & -13.2783 & 0.0000 \\
\hline
\end{tabular}

Null hypothesis: presence of Unit Root

MacKinnon (1996) one-sided $p$-values.

Table 4.2 Taylor rule estimates, 1998Q1-2005Q2

Dependent Variable: Interest Rate (Fed Fund rate)

\begin{tabular}{llcc}
\hline Least squares & & & \\
Inflation & 0.082 & -0.0356 & -0.04328 \\
p. value & 0.196 & 0.687 & 0.6332 \\
Output gap & 0.336 & 0.422 & 0.444 \\
p. value & 0.0001 & 0.000 & 0.001 \\
Interest rate(-1) & 0.913 & 0.879 & 0.8737 \\
p. value & 0.000 & 0.000 & 0.000 \\
Put & & & 0.0213 \\
p. value & & & 0.0741 \\
Call & & 0.0197 & \\
p. value & & 0.0783 & \\
C. R-squared & 0.963 & 0.966 & 0.966 \\
S.E. of regression & 0.3859 & 0.3701 & 0.3695 \\
Obs. & 30 & 30 & 30 \\
Maximum likelihood & & & \\
Inflation & 0.1326 & 0.1439 & 0.2729 \\
p. value & 0.000 & 0.000 & 0.000 \\
Output gap & 0.3057 & 0.4112 & 0.4006 \\
p. value & 0.000 & 0.000 & 0.000 \\
& & & (Continued)
\end{tabular}


Table 4.2 (Continued)

\begin{tabular}{llll}
\hline Dependent Variable: Interest Rate (Fed Fund rate) & & \\
\hline Interest rate(-1) & 0.9391 & 0.8146 & 0.8881 \\
p. value & 0.000 & 0.000 & 0.000 \\
Put & & & 0.015 \\
p. value & & 0.0122 & \\
Call & & 0.000 & \\
p. value & -3.9444 & -4.2663 & -3.2761 \\
Log likelihood & 0.4629 & 0.5511 & 0.4851 \\
Akaike & 30.0000 & 30.0000 & 30.0000 \\
Obs. & & & \\
Variance equation & -0.0008 & 0.0000 & 0.0014 \\
C & 0.8587 & 0.9574 & 0.8050 \\
p. value & 2.3509 & 1.9847 & 2.3168 \\
Resid(-1)^2 & 0.0097 & 0.0163 & 0.0258 \\
p. value &
\end{tabular}

\section{Notes}

1 See Oldani and Savona (2005) on the use of derivatives by European governments, and Oldani (2004) for a survey on the use of derivatives in economic policy.

2 See Sargent and Wallace's (1975) indeterminacy rule in Woodford (2003: 45).

3 Derivatives are efficient assets and have some special characteristics, such as price discovery and matching price.

4 See the appendix for an outline of the main derivatives pricing rules.

5 See Woodford (2003: 721).

6 For a definition of implied volatility refer to the appendix.

7 According to the Federal Reserve Board members and the president, the closest attention was paid to economic growth, asset prices, and financial market stability. From 2006 on the Fed Chairman, Ben Bernanke, has been more concerned with inflationary pressures due to energy prices.

8 See Carare and Tchaidze (2005) for a survey of results.

9 This practice is used in the econometric literature to check for robustness.

10 The implied volatility of options was estimated separately in the function, since considering put and call options together yields statistical insignificant results because of the Put-Call parity used to compute the implied volatility.

11 Unit root tests are provided in Appendix E, Table A4.1.

12 As observed by Carare and Tchaidze (2005), having non-stationary variables in the Taylor rule raises a number of econometric problems. The VAR-VECM approach, widely used to consider this behaviour in the econometric literature, needs a longer length of data, with the consequence that the OLS and ML were chosen. The order of the ML-ARCH was selected according to the Akaike Information criteria. 
13 This is confirmed by the magnitude of the coefficient of the output gap.

14 The variance equation gives positive and significant coefficient of squared residuals, as expected.

\section{References}

Black, F. (1976) 'The Pricing of Commodity Contracts', Journal of Financial Economics, 3, 167-79.

Black, F. and M. S. Scholes (1973) 'The Pricing of Options and Corporate Liabilities', Journal of Political Economy, 81(3), 637-54.

Brenner, M. and M. G. Subrahmanyam (1988) 'A Simple Formula to Compute the Standard Normal Deviation', Financial Analysts Journal, 44(5), 80-3.

Carare, A. and R. Tchaidze (2005) The Use and Abuse of the Taylor Rule: How Precisely Can We Estimate Them? IMF Mimeo, March.

Carlson, J. B., W. R. Melick and E. Y. Sahinoz (2003) An Option for Anticipating Fed Action, Federal Reserve Bank of Cleveland, Cleveland, September.

Estrella, A. (2001) Financial Innovation and the Money Transmission Mechanism, Working Paper, Federal Reserve Bank of New York, New York.

Federal Reserve Bank, Board of Governors, Speeches www.federalreserve.gov, Washington, DC.

Kearney, A. K. and R. E. Lombra (2004) 'Stock Market Volatility, the News and Monetary Policy', Journal of Economics and Finance, 28(2), 252-9.

Oldani, C. (2004) I derivati finanziari: dalla Bibbia alla Enron. Milan: F. Angeli.

Oldani, C. and P. Savona (2005) 'Derivatives, Fiscal Policy and Financial Stability', The ICFAI Journal of Derivatives, 2(3), 7-25.

Savona, P. (2003), La finanza dei derivati, Enciclopedia del Novecento, vol. XII, Supplemento III, Istituto dell'Enciclopedia Italiana.

Vrolijk, C. (1997) Derivatives Effect on Monetary Policy Transmission, IMF Working Paper no. 121, Washington DC: IMF.

Wicksell, K. (1898) Interest and Prices. London: Macmillan.

Woodford M. (2003) Interest and Prices: Foundations of a Theory of Monetary Policy. Princeton, NJ: Princeton University Press. 